\title{
Escolhas de vida pós-ensino médio e representações sociais da universidade pública
}

Choices of life after high school and social representations of the public university

Opciones de la vida después de la escuela secundaria y representación social de la universidad pública

\author{
David A. Romeros de Assis ${ }^{*}$ \\ Carlos Henrique Souza Gerken ${ }^{* *}$
}

\begin{abstract}
Resumo
Este artigo é produto da pesquisa de mestrado intitulada "Escolhas de vida e representaçóes sociais da universidade pública entre jovens ex-alunos da escola pública". Essa investigação foi realizada com 36 ex-alunos de uma escola pública de São João del-Rei (MG) e teve como referência a teoria das representaçóes sociais de Moscovici (1978; 2003). O objetivo foi investigar de que forma a universidade pública é representada por sujeitos que cursaram a escola pública e como essas representações sociais se relacionam com suas escolhas de vida efetivadas depois de cursarem o ensino médio. Utilizou-se de questionário e entrevista semiestruturada para levantamento dos dados e exame de conteúdo para análise das representaçóes sociais. Os resultados nos levam a concluir que as representações sociais da universidade pública construídas por egressos da escola pública interferem na relação dos sujeitos com essa universidade, não de forma mecânica, determinista, mas oferecendo aos sujeitos elementos para orientar e justificar sua ação.
\end{abstract}

Palavras-chave: Representação social, ensino superior, direito à educação.

\begin{abstract}
This article is the product of master's degree dissertation entitled life choices and social representations of public universities among young expupils of public schools. This study was conducted with 36 ex-pupils of a public school of a São João del-Rei (MG) and used the theory of social representations in Moscovici as a reference $(1978,2003)$. The objective was the investigation of the way public university is represented by individuals who attended public schools and how these representations relate to their life choices after high school. A questionnaire and
\end{abstract}

Texto recebido em janeiro de 2011 e aprovado para publicação em julho de 2011.

Psicóloco, consultor de projetos sociais. E-mail: dhaviix-social@yahoo.com.br.

** Doutor em Psicologia, membro do Departamento de Psicologia da Universidade Federal de São João del-Rei (UFSJ). 
semistructured interviews were used to collect data and content analysis was used in order to analyze the social representations. The results lead us to conclude that the social representations built by the egresses from public schools about the public university affect the relationship between subjects and the public university, not in a mechanical and deterministic fashion but by offering subject elements to guide and justify their action.

Keywords: Social representation, higher education, right to education.

\section{Resumen}

Este artículo es fruto de una investigación de maestría titulada opciones de la vida y las representaciones sociales de las universidades públicas entre los jóvenes egresados de las escuelas públicas. Esta investigación se llevó a cabo con 36 ex alumnos de escuelas públicas de São João del-Rei (MG) y se baseo en la teoría de las representaciones sociales de Moscovici $(1978,2003)$. Se propuso investigar la forma en que se representó a la universidad pública por personas que asistieron a escuelas públicas y cómo estas representaciones se relacionan con sus opciones de vida después de la secundaria. Se utilizaron cuestionario y entrevistas semiestructuradas para recopilar datos y análisis de contenido para analizar las representaciones sociales. Los resultados nos llevan a concluir que las representaciones sociales construidas por los graduados de las escuelas públicas afectan a la relación entre los sujetos y la universidad pública, no mecánicamente o determinista, sino que proporcionar elementos que permitam a las personas guiar y justificar su acción.

Palabras clave: Representación social, educación superior, derecho a la educación.

ste artigo é produto da pesquisa de mestrado intitulada "Escolhas de vida e representaçóes sociais da universidade pública entre jovens ex-alunos da escola pública”. Tal pesquisa foi realizada com 36 ex-alunos alunos de uma escola pública de São João del-Rei (MG). O objetivo foi investigar de que forma a universidade pública é representada por sujeitos que cursaram a escola pública e como essas representações sociais se relacionam com suas escolhas de vida efetivadas depois de cursarem o ensino médio, perguntando-nos também quais são as razões sociais e simbólicas de tais escolhas e as estratégias mobilizadas para efetivá-las. $\mathrm{O}$ intento foi identificar, para além das questões objetivas, as questões simbólicas que podem se constituir em obstáculos para que esses sujeitos ingressem na universidade pública (Assis, 2010). 
Acredita-se que a questão do acesso ao ensino superior seja parte de uma problemática mais ampla, qual seja, a da inserção do jovem que conclui o ensino básico na sociedade às possibilidades de conquistas que se abrem para o seu futuro, bem como os limites que estão colocados a partir do seu lugar social. Esse foi o nosso ponto de partida e dele caminhamos para a especificidade do acesso do aluno proveniente da escola pública à universidade pública na atualidade.

Atualmente temos um grande número de brasileiros em idade escolar que está cursando o ensino médio. É um direito do cidadão, garantido pela Constituição Federal de 1988 e reafirmado na Lei no 9.394, de 20 de dezembro de 1996, que estabelece as diretrizes e bases da educação nacional (LDB), nas quais se defende a universalização do ensino básico e, mais especificamente, está prescrito que é atribuição do Estado a garantia da progressiva universalização do ensino médio gratuito.

Contudo a expansão desse nível de ensino para amplos setores da sociedade é um fenômeno recente na história da educação no Brasil. Segundos dados do IBGE, em 1968, o número de matrículas iniciais para esse nível de ensino era de 801 075, o que representava apenas 0,90\% da população. Já em 2001, o número de matrículas havia aumentado em 1 121\% e eram registrados 8983 866. Esse número significa um aumento real, pois a população cresceu $189 \%$ no período (Bachetto, 2003). Com os dados mais atuais disponibilizados pelo INEP, é possível precisar que, em 2008, havia 10016284 alunos matriculados no ensino médio, números que abarcam também esse segmento na modalidade de educação de jovens e adultos (EJA) (INEP, 2010).

Com a expansão do ensino médio ocorrida nas últimas décadas, vimos o número de concluintes desse nível de ensino chegar em 2008 com mais de 2 milhôes de alunos. Destes, 85,5\%, ou 1784435 de alunos, concluíram o ensino médio na escola pública (INEP, 2010). A escola pública é abrangente e diversa. Abriga estudantes de vários setores sociais, mas concentra principalmente os estudantes oriundos de famílias que têm os menores rendimentos da população (último quinto). Nesse momento de encerramento do ensino básico, a maioria desses egressos, jovens com idade entre 17 e 24 anos e, em grande parte, oriundos das camadas populares, precisa enfrentar os problemas trazidos pela necessidade de decidir sobre os caminhos a seguir no futuro. Torna-se imprescindível para esses jovens a construção de um projeto de futuro que implica a efetivação de escolhas capazes de lidar com as incertezas e dificuldades de realização dos desejos frente às necessidades sociais, econômicas e culturais que pressionam os sujeitos. $\mathrm{O}$ resultado do 
enfrentamento das contradições psicossociais que envolvem esse período da vida, além de contribuir para a formação identitária, refletirá diretamente na saúde mental dos sujeitos.

Para efetuar tais escolhas, a dimensão do trabalho apresenta-se como fundamental na vida desses sujeitos. Para jovens estudantes investigados por Raitz \& Petters (2008), a falta de trabalho representa angústia e frustração, consistindo, segundo as autoras "um dos maiores problemas da vida juvenil" (p. 413). Guimarães (2005) também cita a importância do trabalho na vida dos jovens:

[...] instigados a manifestarem-se com respeito ao significado e à importância de diferentes esferas de atividade e sociabilidade, os jovens brasileiros ouvidos em pesquisa amostral representativa realizada em 2003 não deixam dúvidas; para eles, o trabalho não apenas ainda está na ordem do dia, como se destaca com relação a outros aspectos tidos como reveladores de interesses "tipicamente juvenis" (p. 150).

Contudo, na atualidade, a relação dos jovens com o mundo do trabalho constitui um grave problema mundial, demandando a criação de políticas públicas específicas para lidar com a questão. No Brasil, um recurso para o enfretamento do problema é promover um aumento da escolarização do jovem, para que ele possa adiar sua entrada definitiva no mercado de trabalho e se qualificar para pleitear postos de trabalho mais reconhecidos e com melhor retorno financeiro e pessoal (Rocha, 2008). Para tanto, é necessário expandir, ainda mais, as matrículas no ensino superior e torná-lo um espaço mais democrático, uma vez que existem extratos da população que estão excluídos desse nível de ensino.

Mesmo que ainda longe do desejável, houve, nos últimos anos, um aumento expressivo das vagas no ensino superior e de adesão às políticas de ação afirmativa que vêm tornando-o um espaço mais democrático. Por causa dessas mudanças, as oportunidades dos jovens oriundos de escolas públicas ingressarem em uma universidade pública são bem maiores hoje do que há dez anos. Mas o aumento das possibilidades de escolarização por meio da universidade pública é apenas mais um elemento a ser considerado nas escolhas dos sujeitos. A possibilidade de ingresso na universidade pública concorre com uma série de outros fatores vinculados, sobretudo, às necessidades imediatas postas pelas condições materiais das famílias dos jovens (Bastos, 2005). Com base nesse contexto e no pressuposto que a escolarização em uma universidade pública pode ser uma opção bastante vantajosa para os jovens oriundos da escola pública é que construímos nosso problema de pesquisa, 
que pode ser resumido na seguinte questão: quais as razões que interferem para que ex-alunos do ensino médio oriundos de escola pública considerem a possibilidade de dar continuidade à carreira estudantil em uma universidade pública?

A fim de responder a essa questão, optou-se por investigar uma dimensão simbólica do problema, aquela construída na relação dialética entre o psicológico e o social. Para tanto, a fundamentação teórica da pesquisa se dá com base na teoria das representaçôes sociais de Serge Moscovici (1978; 2003), com a complementação de Jean-Claude Abric (1998) e Denise Jodelet (2001; 2005), para quem a representação social "é uma forma de conhecimento, socialmente elaborada e partilhada, com um objetivo prático, e que contribui para a construção de uma realidade comum a um conjunto social" (Jodelet, 2001, p. 22).

Não se diferenciam as representações sociais de outras teorias-chave da Psicologia e da Psicologia social exclusivamente na conceituação. Tampouco na descrição das circunstâncias e dos agentes que são seus produtores. É na ênfase de sua função que a teoria ganha singularidade no campo. As funções são a ação (elaboração de comportamento) e a comunicação entre os indivíduos, e se assemelham a uma bússola a guiar os sujeitos nas realidades que vivenciam ou conhecem, e mesmo transformando aquilo que é novo, diferente ou desconhecido, em um objeto do qual se tem algum conhecimento (Moscovici, 1978; 2003). Nesse sentido, Moscovici acredita que "a finalidade de todas as representações é tornar familiar algo não familiar, ou a própria não familiaridade" (2003, p. 54).

Os universos consensuais dos grupos são ambientes simbólicos nos quais todos querem ter o signo da pertença, de modo a temer e evitar o risco ou o conflito gerado pelo objeto estranho, pelo não familiar, aquilo que corta as possibilidades de comunicação e interação grupal. De uma forma ou de outra, todos fazem parte de círculos de ciência cotidiana, nos quais são criados, negociados e metamorfoseados conceitos e teorias leigas, porém ricas de lógica. Essa ciência cotidiana permite aos sujeitos comunicarem adequadamente no grupo, bem como agir de maneira coerente nele (Moscovici, 1978; 2003).

Baseados nesses conceitos, a nossa hipótese de pesquisa é que as representações sociais construídas sobre a universidade pública ajudam a orientar o sentido das escolhas desses ex-alunos após o ensino médio e podem fazer com que a opção de continuidade dos estudos em uma universidade pública seja ou não considerada, de modo a encontrar diferentes representações conforme a escolha realizada. Para a verificação da hipótese, foram elaborados 
quatro objetivos específicos, quais sejam: (a) investigar as escolhas de vida efetuadas pelos sujeitos, (b) investigar as razôes de suas escolhas, (c) investigar as estratégias que foram utilizadas para efetivá-las e (d) investigar as representações sociais que foram construídas sobre universidade pública e suas articulações com as respectivas escolhas.

\section{Metodologia}

Os sujeitos da pesquisa faziam parte da população de ex-alunos do terceiro ano do ensino médio de uma escola pública de São João del-Rei. Foram escolhidos por causa da localização da escola e pelo fato de esses ex-alunos terem participado, em 2007, de outra investigação a respeito das representações sociais construídas sobre a universidade pública, porém sob o ponto de vista de estudantes da escola pública (Assis \& Silva, 2008). A escola em questão localiza-se em uma das principais vias da cidade e acolhe alunos de diversos bairros, com diferentes perfis sociais. Também está próxima a dois campi da Universidade Federal de São João del-Rei.

O número de sujeitos que efetivamente aceitou participar da pesquisa é de 36 ex-alunos. Eles foram abordados em duas fases distintas. A primeira consistiu em aplicar um questionário com informações mais gerais e determinar quais foram as escolhas em relação à universidade pública. $\mathrm{Na}$ segunda fase da coleta de dados, elegemos dentre os 36, 12 sujeitos que foram classificados em duas configurações diferentes: sujeitos que fizeram vestibular e conseguiram passar em uma universidade pública e sujeitos que não prestaram vestibular nem para instituições públicas e nem privadas. Com esses sujeitos, fizemos entrevistas semiestruturadas, a fim de identificarmos mais profundamente as razões de suas escolhas, as estratégias para efetiválas e os elementos de suas representaçóes sociais a respeito da universidade pública.

A análise dos dados produzidos com o questionário da primeira fase foi essencialmente quantitativa. Os resultados das análises da entrevista semiestruturada da segunda fase foram analisados de duas formas distintas. Na primeira, foi feito o levantamento das razóes e estratégias para a efetivação das escolhas. Na segunda, foi utilizada a análise de conteúdo para identificar as representações sociais da universidade pública construída pelos grupos. Nosso procedimento de análise de conteúdo reconstruiu as representações na dimensão semântica. Preocupava-nos, nas entrevistas, o sentido que era dado ao texto, o que estava realmente sendo dito. Esse procedimento pode ser chamado de análise temática de conteúdo. Para tanto, seguimos o 
método proposto por Bardin (1977) e orientação prática de Ferreira (2000), Franco (2005) e Oliveira (2008).

\section{Resultados e discussão}

Em relação ao gênero, a totalidade dos sujeitos é composta por 23 mulheres $(63,9 \%)$ e 13 homens $(36,1 \%)$. A idade média era de aproximadamente 20 anos. Não houve grande variação, pois os mais novos tinham 18 anos e os mais velhos, 21. Quase todos os sujeitos estavam solteiros e não tinham filhos, com exceção de uma ex-aluna que se encontrava em união estável com um companheiro e que declarou ter um filho. A grande maioria dos sujeitos $(97,2 \%)$ ainda morava com a mãe ou o pai.

A resposta ao primeiro objetivo específico foi importante para que pudéssemos separar em grupos sujeitos que efetuaram diferentes escolhas em relação ao seu possível ingresso na universidade pública. Do nosso conjunto de 36 sujeitos, 7 prestaram vestibular em uma universidade pública e foram aprovados, 14 prestaram vestibular e não obtiveram êxito, e outros 15 não prestaram vestibular. Ampliando a questão das escolhas, pode-se observar que houve um grande movimento em direção ao ensino superior, com 22 sujeitos prestando vestibular e 11 obtendo êxito ( 4 em instituiçôes privadas). Conforme ficou claro na pesquisa, o movimento dos sujeitos em direção ao ensino superior é ancorado sobre uma expectativa de melhoria das condições de inserção no mercado do trabalho. Considerando essa perspectiva e a adesão a cursos de qualificação e ou profissionalizantes, podemos dizer que as escolhas de $97 \%$ dos sujeitos envolveu alguma forma de mobilização em direção ao mundo do trabalho.

Para responder aos outros objetivos específicos, separamos 2 grupos com 6 sujeitos cada, que fizeram escolhas opostas em relação à universidade pública. Excluímos da nossa amostra os ex-alunos que tentaram vestibular na universidade pública e não passaram. Acreditamos que todos os alunos que prestaram vestibular fizeram um movimento significativo de busca ou mesmo de conhecimento de uma nova possibilidade de futuro frente às alternativas que se colocam ao final do ensino médio. Contudo, para melhor vermos as razôes, os contrastes e as contradições envolvidas na situação, pareceu-nos mais oportuno investigar os dois polos opostos da questão das escolhas, ou seja, o grupo dos alunos que prestou vestibular e ingressou na universidade pública (grupo U) e o grupo que não tentou vestibular em nenhuma universidade (grupo N). O critério de delimitação do grupo foi o de tentar entrevistar todos do grupo $\mathrm{U}$ e fazer o mesmo número de entrevistas efetivadas com o 
grupo N. Como um sujeito do grupo U não teve disponibilidade para a entrevista, o número foi de seis sujeitos em cada grupo.

Os resultados mostram que as razões manifestas para as escolhas dos sujeitos (segundo objetivo específico) são as mais diversas, mas algumas constâncias aparecem na análise mais acurada das entrevistas. Três sujeitos do grupo $\mathrm{N}$ manifestaram um "cansaço" em relação ao mundo escolar, e essa teria sido a principal razão de suas escolhas de não continuar os estudos e ingressar no mercado de trabalho. Em outros casos, pôde-se perceber a necessidade de responder imediatamente às demandas da falta de recursos materiais e econômicos. Contudo o aspecto que mais chamou a atenção foi o fato de a escolha de não tentar o ingresso na universidade pública não figurar como definitiva pelos sujeitos. Para 5 ex-alunos, a decisão de não prosseguir os estudos é temporária e contingenciada pelas condições socioeconômicas.

Para os sujeitos do grupo U, as principais razões manifestas das escolhas estão relacionadas à gratuidade do ensino, que representa uma oportunidade para os jovens, e ao diploma da universidade pública, considerado importante para um ingresso diferenciado no mercado de trabalho. No entanto, um elemento aparece claramente no discurso dos sujeitos: a presença de um outro (que pode ser um parente próximo, um amigo, ou mesmo a figura dos pais) que inspira, apoia e funciona como referência na luta pela escolarização. Essa presença do outro, exercida também pelas vias da solidariedade material, é um complemento oportuno e fundamental às estratégias de ex-alunos de escolas públicas dos meios populares (Portes, 2000). Sendo uma referência afetiva, e ou suporte econômico e financeiro, torna o caminho em direção à universidade pública mais significativo simbolicamente, menos árduo e mais factível, ajudando a formar representações sociais diferenciadas de seus pares. Segundo Doise (2001), "Cada indivíduo tem vários grupos de pertença: alguns deles servirão mais de pontos de ancoragem de suas opiniōes e crenças do que outros" (p. 194). O autor completa: "Grupos aos quais um indivíduo não pertence, mas a que aspira pertencer, podem também desempenhar um papel de ancoragem" (p. 194).

Saber quais foram as estratégias dos sujeitos para a efetivação das escolhas foi o terceiro objetivo específico. Todos os sujeitos do grupo $\mathrm{N}$ haviam ingressado no mercado de trabalho. Para conseguir suas colocações, lançaram mão de vários recursos, como cursos de qualificação e envio de currículos para as empresas. No momento em que se colocam à disposição do mercado de trabalho, começam a ter atitudes em busca de um emprego e criam uma percepção voltada para as oportunidades de colocação profissional. 
Enfrentam, todavia, as dificuldades relativas à falta de experiência que adiam sua entrada no mercado de trabalho, gerando ansiedade e frustração para esses jovens.

Por sua vez, vários sujeitos do grupo U se valeram do curso preparatório para o vestibular. Diante da necessidade de complementação do ensino recebido na escola pública e uma orientação específica para o vestibular escolhido, o "prévestibular" caracteriza-se como uma estratégia fundamental e amplamente utilizada pelos sujeitos. Outra estratégia construída na trajetória escolar é a dedicação diferenciada aos estudos no ensino médio. Isso nos remete ao raciocínio de que alunos motivados para o ingresso na universidade pública podem aproveitar melhor o ensino que lhes é oferecido, no sentido contrário à falta de interesse ou à adesão às formas alternativas de não participação percebidas no ensino médio (Pazello, Cabral \& Cazolla, 2010).

\section{As representaçōes sociais da universidade pública}

$\mathrm{O}$ quarto e principal objetivo específico da pesquisa foi investigar as representações sociais da universidade pública construída pelos sujeitos. A análise das representações sociais corrobora nossa hipótese de pesquisa. Observou-se nitidamente uma diferença nas representações sociais da universidade pública entre os diferentes grupos analisados, tanto no número quanto na organização de seu conteúdo, e essas diferenças se articulam com as escolhas efetuadas por essas pessoas. Ou seja, o conhecimento cotidiano e prático construído socialmente em relação ao objeto "universidade pública" funciona como orientação para as escolhas de vida feitas pelos sujeitos. Para os sujeitos do grupo U, a representação social da universidade pública serve como suporte de uma mobilização para o ingresso na instituição. Para os ex-alunos do grupo $\mathrm{N}$, essa representação constitui um obstáculo simbólico para o ingresso e contribui para justificar escolhas que afastam os sujeitos da perspectiva do acesso a essa instituição.

As representações encontradas apontam para a identidade diferenciada de grupos dentro da escola pública, e estes convencionam o objeto conforme seu ambiente social (Moscovici, 2003). Entretanto, o objeto da representação social também é ativo e intervém na constituição identitária, abrindo espaço para a mudança. $\mathrm{O}$ que significa que a representação social não é a causa estrita de um comportamento ou somente um guia para a ação, mas interfere nesse processo, "sobretudo na medida em que remodela e reconstitui os elementos do meio ambiente em que o comportamento deve ter o seu lugar" (Moscovici, 1978, p. 49). 
Podemos sintetizar as representações sociais indicando que, no grupo N, a universidade pública é representada como uma "instituição muito difícil de ingressar, embora socialmente importante". A questão da alta relevância e domínio do conteúdo "obstáculo para o ingresso" ajuda a entender o quanto a representação social da universidade pública pode ser obstáculo subjetivo para a luta dos sujeitos do grupo $\mathrm{N}$, que valorizam e manifestam, em sua maioria, interesse pela universidade pública. "Acho que é muita, muita... gente pra concorrer e é bem difícil' (Rebeca). ${ }^{1}$ Para os vestibulares, diploma de ensino médio não significa ter conhecimento, não há um nivelamento por meio dele, e sim, extrema desigualdade, conforme a origem da certificação. Parece que a consciência dessa diferença de valor atribuído à certificação ajuda na produção de representaçôes ligadas à dificuldade de acesso. Nesse sentido, Zago (2006, p. 231) fala sobre estudantes universitários oriundos das camadas populares que tinham "uma apreciação muito crítica sobres suas chances objetivas" em relação ao vestibular.

A ausência de conteúdos descritivos da instituição e a explicitação de desconhecimento das características do objeto, em alguns momentos, denotam, ainda, que a informação circulou de forma diferente no grupo que manifestou um menor interesse em relação à universidade pública.

Para os membros do grupo $\mathrm{U}$, a representação social da universidade pública poderia ser sintetizada em "melhor caminho para a realização profissional, pela qualidade e reconhecimento social da instituição, que exige muito esforço para ingressar, mas vale a pena, uma vez que o ensino é gratuito e que, por ser pública, deveria servir prioritariamente à população mais desprovida de condições materiais". A universidade pública é representada como uma oportunidade de conquistar melhores posições no concorrido mercado de trabalho. É pensada como oportunidade devido à valorização que é dada pelo mercado à titulação e pelo fato de não ter ônus financeiro, o que poderia inviabilizar tal projeto: "Porque, às vezes, é o mesmo curso, as mesmas disciplinas, mas a pessoa que tem no currículo a universidade pública vai ser escolhida... assim por currículo, né?" (Rafaela). "Porque, se eu fosse fazer um curso de Zootecnia ou Veterinária particular, minha condição financeira... pai ia ficar muito apertado" (Renata). Concebem ainda que o ingresso na instituição envolve empenho e dedicação, e reivindicam esse espaço para as faixas mais pobres da população: "Pensava que, por ser pública, era mais pessoas de baixa renda, né. Mas aqui dentro você vê, conhecendo as pessoas, que ainda tem isso. Pessoas que tiveram a oportunidade de estudar mais numa escola melhor que

Para preservar a identidade dos sujeitos entrevistados, os nomes utilizados são fictícios. 
conseguem entrar" (Robson). Todos esses elementos acabam por dar suporte (mesmo que, às vezes, de forma contraditória) à mobilização para o ingresso em uma universidade pública.

A teoria das representações sociais se revela adequada para a compreensão da dimensão simbólica das escolhas de vida de jovens oriundos da escola pública, por se tratar de uma forma de conhecimento que orienta as condutas e que rege a relação dos sujeitos com o mundo (Jodelet, 2001). Dessa forma, permite-nos refletir sobre como esse conhecimento construído cotidianamente pode favorecer ou não a mobilização de jovens procedentes da escola pública rumo ao ingresso em uma universidade pública. Nesse sentido, chama-nos a atenção a ausência de conteúdos relativos à universidade pública que são importantes para mediar sua relação com a escola pública e que não são mencionados em nenhum dos dois grupos, como, por exemplo, políticas de permanência oferecidas pela universidade (diversas formas de auxílio estudantil), a relação da universidade com a pesquisa e extensão e, principalmente, o novo contexto dos programas de ação afirmativa que tem um impacto direto nessa população. Essa ausência é importante, pois demonstra haver um espaço para a construção de novos conhecimentos que aproximem os jovens da universidade púbica, como em uma das ações de um programa de extensão relatado por Menezes et al. (2010), na qual os bolsistas "não iam para as escolas a fim de levar resposta e ou solucionar problemas, mas sim para problematizar a vivência ou não da cidadania, o acesso aos direitos e a democratização da universidade, junto à comunidade" (p. 136). Os resultados apontam que, para além de se atentar para a diferença na circulação das informações nos grupos dentro da escola, há também a necessidade de uma reflexão sobre os efeitos do tipo de informação que chega à escola pública acerca da universidade pública e sobre o quanto uma informação formal ou institucional tem penetração na escola.

Roberto, do grupo U, que diz ter escolhido ingressar na universidade pública após ter participado de um projeto no qual ele foi apresentado à instituição, ainda assim reclama da falta de acesso às informações na escola pública:

Eu penso que podia ter antes, no... tipo no ensino médio e até no ensino fundamental, tinha que ter um contato assim para você já ter... ir sabendo um pouco cara... não sei... você familiarizar com o ambiente e tal... Porque é muita coisa que você não aproveita até porque você chega aqui e você não sabe... você não tem informação, você chega meio perdido (Roberto). 
É emblemático o caso de um dos sujeitos, entrevistado dentro da universidade, que declarou não saber que havia uma "universidade pública" com ensino gratuito: "Eu pensava que era assim, entrou na faculdade e paga e tal, e tal... mas eu não sei como é que é isso" (Rose). Nascimento (2009), ao investigar as aspiraçôes de jovens das camadas populares ao ensino superior, verifica que os sujeitos dificilmente conseguiam informações sobre as instituições, carreiras e formas de acesso à universidade pública na escola, tal como na família e grupos de amigos. Contudo, ao entrarem em contato com essas informações, os sujeitos passavam a aspirar à educação superior e "a se organizar de forma a percorrer o longo caminho até a matrícula num curso superior" (p. 134). Os sujeitos da pesquisa de Nascimento (2009) eram estudantes de cursos pré-vestibulares populares. Evidentemente que as informações não impactam igualmente todos os alunos do ensino básico público, mas há um potencial que não pode ser negado.

\section{Considerações finais}

Ao analisar os resultados da pesquisa, concluímos que as representações sociais da universidade pública construídas por ex-alunos oriundos da escola pública influenciam as escolhas desses sujeitos em relação ao ingresso na instituição. $\mathrm{O}$ estudo demonstrou ainda que as escolhas dos sujeitos, em sua grande maioria, estão relacionadas à necessidade de ingresso dos jovens no mundo do trabalho, apontando para uma demanda de discussão e reflexão sobre a inserção dos jovens nas práticas sociais após terminarem o ensino médio.

Utilizando uma perspectiva de desenvolvimento da consciência relacionado à pesquisa das representaçôes sociais (Franco, 2004), podemos dizer que representações sociais da universidade pública que contemplem o maior número de aspectos institucionais, mais coerentes com a realidade e menos idealizados, favorecerão decisões mais satisfatórias e maduras em relação às escolhas de vida dos jovens egressos da escola pública. Ou seja, optem ou não pela universidade pública, terão condições de elaborar melhor suas escolhas. Tais representações poderão significar, ainda, pela nova configuração do quadro de oportunidades de acesso ao ensino superior, uma aproximação maior desses jovens com a universidade pública.

Porém a tarefa de estimular a criação de novas representações sociais que favoreçam a mudança não é fácil. Em certa medida, depende tanto da instituição (objeto das representaçôes) quanto dos sujeitos, agindo de forma conjunta na construção do conhecimento. Para tanto, é necessário que o objeto 
(universidade pública) se torne cada vez mais socialmente relevante para os sujeitos. O que provoca a mudança "tem que partir ao mesmo tempo do preexistente e do esperado, recorrer não só ao contexto imediato, mas também ao passado e à expectativa do futuro" (Arruda, 2002, p. 69). A universidade pública reúne um conjunto de aspectos que a reveste de relevância para os alunos de escola pública, tanto no que se refere à qualidade da formação profissional quanto da formação cultural e humana. Não apenas pode contribuir com a construção de um futuro melhor para esses alunos, como tem se transformado nos últimos anos, para se tornar mais acessível a esse público. Contudo, pela dinâmica própria de transformação das representaçôes sociais, é possível que as representações ainda resistam à adequação ao novo contexto, conforme o objeto não se impõe para esse público.

Vimos neste trabalho que as oportunidades de ex-alunos de escola pública ingressarem no ensino superior são maiores atualmente do que há dez anos, sobretudo no que se refere à universidade pública. Num passado recente, tínhamos um cenário de uma instituição muito pouco permeável aos egressos de escola pública, que, em sua maioria, representam os estratos mais pobres de nossa população. A mudança de cenário se deu com o aumento de vagas, mudanças nos processos seletivos e, principalmente, a adesão às políticas de democratização do acesso.

Contudo podemos questionar se as representações sociais da universidade pública de alunos da escola pública estão se transformando para incorporar o novo contexto. Os resultados de nossa investigação não nos fornecem indícios de uma transformação substantiva, ou seja, não foram encontrados nos discursos dos sujeitos os elementos característicos da nova realidade. Há dois mecanismos da dinâmica das representações sociais que nos permitem tecer algumas consideraçóes sobre o fenômeno. $\mathrm{O}$ primeiro diz respeito ao núcleo central das representações sociais. Não foi nossa intenção, neste trabalho, identificá-lo, mesmo porque o número de sujeitos não era adequado a esse tipo de pesquisa. Todavia o conhecimento de sua dinâmica pode nos ajudar a entender os resultados encontrados. O núcleo central é a parte mais rígida e estável de uma representação. "Ele será, dentro da representação, o elemento que mais vai resistir à mudança" (Abric, 1998, p. 31). Julgando que o contexto de oportunidades de escolarização do qual estamos tratando se alterou muito recentemente, o núcleo central das representaçôes sociais da universidade pública de estudantes da escola pública poderia ainda persistir em conteúdos historicamente construídos que remetem, de forma mais coerente, a um quadro de obstáculos contundentes para o ingresso na universidade pública. O que foi real um dia teria se objetivado e atuaria de forma simbólica 
a recriar a "realidade" cotidiana atualmente. Investigar o núcleo central dessas representaçôes em pesquisas posteriores é uma sugestão decorrente desse trabalho.

O segundo mecanismo já foi parcialmente citado neste texto e diz respeito à relevância social do objeto, que está relacionado com a comunicação social. Ou seja, para a emergência das representaçôes de um objeto, ele precisa tornar-se socialmente relevante, de forma ativa para o grupo. Para tanto, é necessário que haja uma aproximação maior das instituições envolvidas, que elas se comuniquem e reflitam sobre o papel dessa relação. Menezes et al. (2010) problematizam essa aproximação:

[...] se verificou que, por mais que garanta uma forma de ascensão social, o espaço da universidade, especialmente a pública, não costuma fazer parte das pretensões de grande parte dos integrantes das comunidades populares. A partir desse diagnóstico, viuse a necessidade de propor ações que abrissem espaço para o questionamento dessa dinâmica social e a democratização do acesso e permanência de estudantes oriundos de camadas populares nas universidades federais (p. 129).

No caso da universidade pública, para a escola pública, a relação ainda é incipiente, demandando um grande movimento de apropriação, problematização e criação de vínculos mais sólidos entre as instituições. A escola pública pode e deve ser proativa nesse processo, mas há uma responsabilidade crucial da universidade pública, que, ao optar por políticas de ação afirmativa, precisa se preocupar também com a atratividade dos melhores talentos da escola pública e com os excluídos desse nível de ensino.

Para os sujeitos da pesquisa que escolheram e se mobilizaram para entrar na universidade pública, a carreira profissional ou o mundo de trabalho se configurou como um elemento fundamental na representação: "É o lugar que você pode receber qualificação não só profissional, mas cultural... sei lá... muito ramos assim...” (Roberto). Esse dado nos fornece preciosa informação sobre o caminho privilegiado para a constituição de representações que aproximem as duas instituições. "Atribuir sentido é uma delicada operação que demanda terra firme onde jogar a âncora" (Arruda, 2002, p. 69). O mundo do trabalho é a terra firme que mais oferece possibilidade de ancoragem para a representação da universidade pública.

Bastos (2005), pesquisando fatores relacionados à escolha profissional de egressos da escola pública, também encontrou uma forte relação entre a emergência da questão profissional e as escolhas que contemplavam o 
ensino superior. Segundo a autora, para os sujeitos investigados, "a discussão em torno da realização de um curso superior girou sempre em torno da questão da inserção profissional, o que é essencial para todas as pessoas, principalmente para aquelas a quem impera a necessidade de trabalhar por questão de sobrevivência" (p. 39-41). A dimensão do trabalho é fundamental para os jovens, especialmente os da escola pública, e a universidade pode ser um meio para conquistar seus objetivos profissionais. A comunicação social das universidades públicas precisa contemplar esse entendimento nas suas relaçôes com a escola pública.

Outro aspecto importante é o oferecimento de referências que permitam a função de identificação da representação. Os sujeitos do grupo $U$, em sua maioria, apresentam referências de longevidade escolar externas à escola. Essa ancoragem mais ampla será possível conforme os alunos tenham acesso a referências de escolarização com as quais consigam se identificar, ou seja, passíveis de serem ancoradas em suas experiências cotidianas.

Como se vê, os resultados encontrados levaram-nos a atentar para o processo de construção das representações sociais que aproximem universidade e escola públicas. Essa opção refere-se à possibilidade de construção de um conhecimento que pode contribuir com políticas públicas de democratização do acesso ao ensino superior. Como bem lembra Jodelet (2001), "a posição ocupada pela representação no ajustamento prático do sujeito a seu meio fará com que seja qualificada por alguns de compromisso psicossocial" (p. 28).

O ensino médio é um momento de escolhas, de transições e decisões que poderão determinar o resto da vida dos alunos. É imperativo que a escola tenha espaços de reflexão sobre essas escolhas e que esses espaços contemplem, de forma coerente e crítica, as diversas possibilidades que se abrem para o futuro dos alunos.

Uma consequência possível da pesquisa é a indicação de nossa experiência extensionista de apresentar criticamente a universidade pública aos alunos da escola pública (Assis et al., 2006) tal como a de Menezes et al. (2010), que problematiza questóes como cidadania e democratização do acesso. Ou ainda a sugestão de Bastos (2005), que propõe a prática de orientação profissional nas escolas como uma iniciativa que "poderia auxiliar os alunos a refletir sobre seu futuro profissional, propiciando um espaço de discussão a respeito do trabalho, preparando o aluno para uma inserção, consciente e crítica no mundo do trabalho" (p. 35). A autora ainda adverte:

A ausência desse tipo de discussão dentro da escola pode fazer com que seus alunos saiam despreparados para a construção de estratégias 
que lhes permitam enfrentar criticamente as dificuldades e buscar novos caminhos na concretização de seus projetos de vida (p. 35).

É preciso avançar na construção de projetos conjuntos entre as duas instituições, que possam ajudar os jovens a se tornarem cada vez mais sujeitos de suas escolhas de futuro pós-ensino médio, sempre se atentando para as representaçōes sociais que circulam no ambiente escolar, pois, de forma dialética, elas podem resistir e ou potencializar a mudança.

Por fim, é importante frisar que não ignoramos que um dos principais fatores que afastam os jovens das camadas populares do ingresso na universidade pública é a falta de qualidade proporcionada pela diminuta atenção dos governantes aos níveis básicos de escolarização no Brasil. Para os que lutam por uma educação de qualidade em nosso País, esse ponto sempre será uma bandeira a ser defendida acima de qualquer outra. Contudo, não podemos esperar de braços cruzados que essa mudança ocorra no curto ou médio prazo e nem incorrer no erro de achar que essa condição por si só resolveria os problemas de inclusão. A investigação do viés subjetivo que potencializa ou amortece o impacto das novas políticas de democratização do acesso, a compreensão das representações sociais que são (re) criadas e da forma como estas ajudam a entender e dar sentido às atitudes dos jovens em relação à sua perseverança na luta pela escolarização superior podem ser uma contribuição bastante útil para o campo.

\section{Referências}

Abric, J-C. (1998). A abordagem estrutural das representações sociais. In: A. S. P. Moreira \& D. C. Oliveira (orgs.). Estudos interdisciplinares de representação social. (pp. 27-38). Goiânia: AB.

Arruda, A. (2002). Subjetividade, mudança e representações sociais. In: O. Furtado \& F. L. G. Rey (orgs.). Por uma epistemologia da subjetividade: um debate entre a teoria sócio-histórica e a teoria das representaçôes sociais. (pp. 6576). São Paulo: Casa do Psicólogo.

Assis, D. A. R. (2010). Escolhas de vida e representaçôes sociais da universidade pública entre jovens ex-alunos da escola pública. Dissertação de Mestrado, Programa de Mestrado em Psicologia, Universidade Federal de São João delRei, São João del-Rei. 
Assis, D. A. R. et al. (2006). Universidade pública na escola pública: incluir e motivar através da informação. Anais do $3^{\circ}$ Congresso Brasileiro de Extensão Universitária. Florianópolis, SC, Brasil.

Assis, D. A. R. \& Silva, M. V. (2008). Representação social do aluno do ensino médio da escola pública acerca de seu ingresso na universidade pública. Anais do VII Congresso de Produção Científica da UFSJ. São João del-Rei: UFSJ.

Bachetto, J. G. (2003). Cursinhos pré-vestibulares alternativos no município de São Paulo (1991-2000): a luta pela igualdade no acesso ao ensino superior. Dissertação de Mestrado, Faculdade de Educação, Universidade de São Paulo, São Paulo.

Bardin, L. (1977). Análise de conteúdo. Lisboa: Edições 70.

Bastos, J. C. (2005). Efetivação de escolhas profissionais de jovens oriundos do ensino público: um olhar sobre suas trajetórias. Revista Brasileira de Orientação Profissional, 6 (2), 31-43.

Doise, W. (2001). Atitudes e representações sociais. In: D. Jodelet (org.). As representaçôes sociais. (pp. 187-203). Rio de Janeiro: Eduerj.

Ferreira, B. W. (2000). Análise de conteúdo. Aletheia (11), 13-20.

Franco, M. L. P. B. (2005). Análise do conteúdo. Brasília: Líber Livro.

Franco, M. L. P. B. (2004). Representações sociais, ideologia e desenvolvimento da consciência. Cadernos de Pesquisa, 34 (121), 169-186.

Guimarães, N. A. (2005). Trabalho: uma categoria-chave no imaginário juvenil? In: H. W. Abramo \& P. P. M. Branco (orgs.). Retratos da juventude brasileira: análises de uma pesquisa nacional. (pp. 87-128). São Paulo: Fundação Perseu Abramo.

INEP. (2010). Sinopse estatística da educação básica - 2008. Recuperado em 14 de abril de 2010, de http://www.inep.gov.br/download/censo/2009/ sinopse_edu_basica_final_09.zip.

Jodelet, D. (2005). Loucuras e representaçôes sociais: investigaçôes em Psicologia social. Petrópolis: Vozes.

Jodelet, D. (2001). Representações sociais: um domínio em expansão. In: D. Jodelet (Org.). As representaçôes sociais. (pp. 17-44). (L. Ulup, Trad.). Rio de Janeiro: Eduerj. 
Menezes, C. S. et al. (2010). Dialogando saberes: universidade pública e comunidade. In: C. Mayorga (org.). Universidade cindida, universidade em conexão: ensaios sobre a democratização da universidade. Belo Horizonte: Editora UFMG.

Moscovici, S. (1978). A representação social da psicanálise. Rio de Janeiro: Jorge Zahar.

Moscovici, S. (2003). Representaçôes sociais: investigação em Psicologia social (4. ed.). Petrópolis: Vozes.

Nascimento, E. P. (2009). Jovens e educação superior: as aspiraçôes de estudantes de cursos pré-vestibulares populares. Dissertação de Mestrado, Faculdade de Educação, Universidade de São Paulo, Ribeirão Preto.

Oliveira, D. C. (2008, outubro-dezembro). Análise de conteúdo temáticocategorial: uma proposta de sistematização. Revista Enfermagem UERJ, 16 (4), 569-576.

Pazello, E. T., Cabral R. \& Cazolla, M. (2009). Conceitos: mapeando formas alternativas de não participação no Ensino Médio. In: W. Engel (org.). A crise de audiência no ensino médio. (pp. 37-44). São Paulo: Instituto Unibanco.

Portes, E. A. (2000). O trabalho escolar das famílias populares. In: M. A. Nogueira, G. Romanelli \& N. Zago (orgs.). Familia \& Escola: trajetórias de escolarização em camadas médias e populares. (pp. 61-80). Petrópolis: Vozes.

Raitz, T. R. \& Petters, L. C. F. (2008). Novos desafios dos jovens na atualidade: trabalho, educação e família. Psicologia \& Sociedade, 20 (3), 408-416.

Rocha, S. (2008). A inserção dos jovens no mercado de trabalho. Caderno CRH, 21, (54), 533-550.

Zago, N. (2006, maio-agosto). Do acesso à permanência no ensino superior: percurso de estudantes universitários de camadas populares. Revista Brasileira de Educação, 11, (32), 226-237. 